\title{
Opposite Regulation of Oligodendrocyte Apoptosis by JNK3 and Pin 1 after Spinal Cord Injury
}

\author{
Qi Ming Li, ${ }^{1,3 *}$ Chhavy Tep, ${ }^{1,2 *}$ Tae Y. Yune, ${ }^{1}$ Xiao Zhen Zhou, ${ }^{4}$ Takafumi Uchida, ${ }^{5}$ Kun Ping Lu, ${ }^{4}$ and Sung Ok Yoon ${ }^{1}$ \\ ${ }^{1}$ Center for Molecular Neurobiology and Department of Molecular and Cellular Biochemistry, ${ }^{2}$ Ohio State Biochemistry Program, and ${ }^{3}$ Ohio State \\ Molecular, Cellular, and Developmental Biology Program, The Ohio State University, Columbus, Ohio 43210, ${ }^{4}$ Cancer Biology Program, Beth Israel \\ Deaconess Medical Center, Harvard Medical School, Boston, Massachusetts 02215, and ${ }^{5}$ Molecular Enzymology, Molecular Cell Science, Graduate School of \\ Agricultural Science, Tohoku University, Sendai-shi 980-8576, Japan
}

\begin{abstract}
Although oligodendrocytes undergo apoptosis after spinal cord injury, molecular mechanisms responsible for their death have been unknown. We report that oligodendrocyte apoptosis is regulated oppositely by c-Jun N-terminal kinase 3 (JNK3) and protein interacting with the mitotic kinase, never in mitosis A I (Pin1), the actions of which converge on myeloid cell leukemia sequence-1 (Mcl-1). Activated after injury, JNK3 induces cytochrome $c$ release by facilitating the degradation of Mcl-1, the stability of which is maintained in part by Pin1. Pin 1 binds Mcl-1 at its constitutively phosphorylated site, $\mathrm{Thr}^{163}$ Pro, and stabilizes it by inhibiting ubiquitination. After injury JNK3 phosphorylates Mcl-1 at Ser ${ }^{121}$ Pro, facilitating the dissociation of Pin1 from Mcl-1. JNK3 thus induces Mcl-1 degradation by counteracting the protective binding of Pin 1 . These results are confirmed by the opposing phenotypes observed between JNK ${ }^{-1-}$ and Pin $1^{-I-}$ mice: oligodendrocyte apoptosis and cytochrome $c$ release are reduced in JNK3 ${ }^{-/-}$but elevated in Pin $1^{-I-}$ mice. This report thus unveils a mechanism by which cytochrome $c$ release is under the opposite control of JNK3 and Pin1, regulators for which the activities are intricately coupled.
\end{abstract}

Key words: JNK; apoptosis; knock-out mice; mitochondria; oligodendrocyte; signal transduction

\section{Introduction}

After spinal cord injury a large portion of proximal oligodendrocytes undergoes apoptotic death during an extended period of time, with up to one-half of the population ultimately lost from the immediate area of injury (Crowe et al., 1997; Beattie et al., 2002). The result of this process is chronic demyelination (Totoiu and Keirstead, 2005). The mechanism by which oligodendrocytes die is, however, still not clear. Some of the extracellular signals that are known to regulate oligodendrocyte apoptosis in vivo include Fas, proform of nerve growth factor (proNGF), and tumor necrosis factor $\alpha(\mathrm{TNF} \alpha)$ (Kim et al., 2001; Beattie et al., 2002; Demjen et al., 2004). These three ligands all activate the c-Jun N-terminal kinase (JNK) pathway as part of their apoptotic signals when they bind their cognate receptors, at least in culture.

The JNK pathways typically are activated by proinflammatory as well as various stress signals in the nervous system (Shaulian and Karin, 2002). Under these conditions in which JNK proteins induce apoptosis, their main action appears to be phosphorylating the activator protein (AP) I family of key transcription factors, such as c-Jun, thereby affecting the expression of their target

Received March 23, 2007; revised June 23, 2007; accepted June 26, 2007.

This work was supported by National Institutes of Health Grants R01: AG022082 (K.P.L.) and R01: NS 39472 ( S.0.Y.), Christopher Reeve Paralysis Foundation, and New York State Spinal Cord Foundation. We thank Dr. Xiaodong Wang for p3XFLAG-CMV-10-Mcl-1 and Dr. Bruce Carter for HA-Ubc.

${ }^{*}$ Q.M.L. and C.T. contributed equally to this work.

Correspondence should be addressed to Dr. Sung Ok Yoon, Center for Molecular Neurobiology, 184 Rightmire Hall, The Ohio State University, 1060 Carmack Road, Columbus, 0H 43210. E-mail: Yoon.84@0su.edu. D01:10.1523/JNEUROSCI.2478-07.2007

Copyright $\odot 2007$ Society for Neuroscience $\quad$ 0270-6474/07/278395-10\$15.00/0 genes (Kallunki et al., 1996; Behrens et al., 1999; Yoshida et al., 2002). In addition, JNK also can regulate the mitochondrial apoptotic pathway directly by facilitating cytochrome $c$ (cytC) release after stress in culture (Tournier et al., 2000).

The physiological conditions that activate the JNK pathway, however, do not always result in an apoptotic response in vivo, suggesting that JNK proteins play diverse roles during development as well as in the adult nervous system (Kuan et al., 1999). Although this may be the case for JNK1 and JNK2, a certain degree of specificity has been observed for JNK3. For instance, JNK3 expression is restricted primarily to the nervous system (Mohit et al., 1995), and knock-out analyses indicate that JNK3 initiates the apoptotic program under a wide range of pathological conditions, such as ischemia (Kuan et al., 2003; Okuno et al., 2004), axotomy (Herdegen et al., 1998; Kenney and Kocsis, 1998), and seizure (Yang et al., 1997) and in animal models of neurodegenerative diseases (Hunot et al., 2004; Brecht et al., 2005). Of the three apoptotic receptors that play roles in oligodendrocyte apoptosis after spinal cord injury, p75, in particular, has been shown to activate JNK3 in oligodendrocyte cultures (Harrington et al., 2002). Whether JNK3 regulates mitochondrial homeostasis in the nervous system and which proteins are the physiological targets involved in cytC release, however, have remained unknown. The goal of the present study was, therefore, to identify the key JNK3 targets and elucidate the mechanisms by which JNK3 regulates these targets to induce apoptosis in vivo.

As a member of the mitogen-activated protein (MAP) kinase family, JNK3 recognizes and phosphorylates serine/threonine 
a

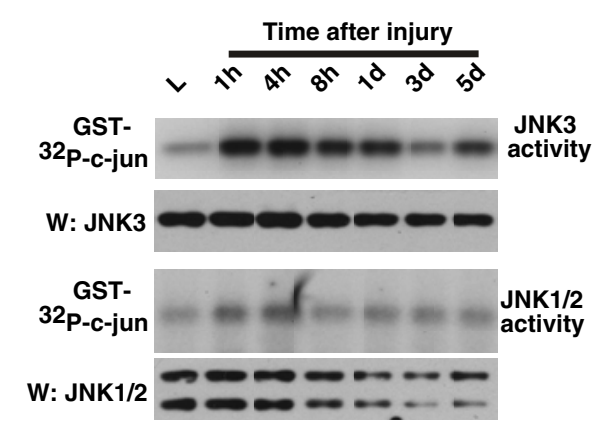

b

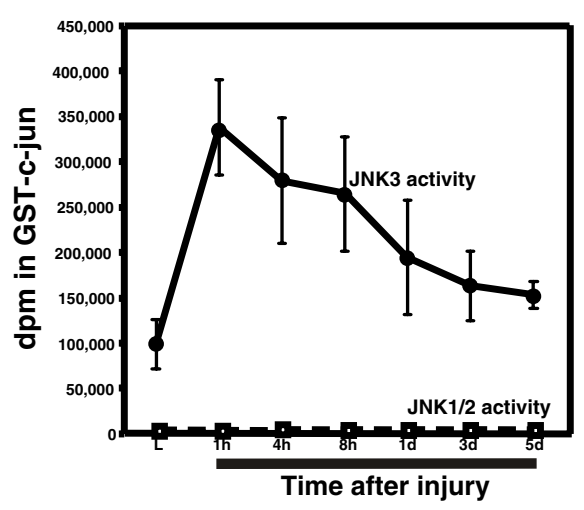

C

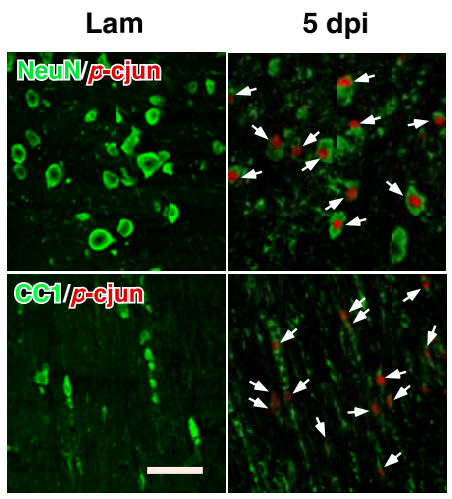

Figure 1. JNK3 is the major kinase activated after spinal cord injury. $\boldsymbol{A}, \boldsymbol{B}$, JNK3 and JNK1/2 activity was measured in immunoprecipitation/kinase assays by using GST-c-Jun as the substrate. For the specificity of JNK3 immunoprecipitation, see supplemental Figure 1 (available at www.jneurosci.org as supplemental material). Note that JNK1/2 activities are at least 500 -fold lower than JNK3 activity, based on the radioactivity counts on GST-c-Jun. $n=3$. The error bars represent the range of the disintegrations per minute counts. $C$, The $p$-c-Jun immunoreactivity, a measure of JNK activation, was detected in oligodendrocytes and neurons after injury. Arrows point to $p$-c-Jun ${ }^{+}$cells. Scale bar, $30 \mu \mathrm{m}$.

(Ser/Thr) in SerPro and ThrPro motifs. These consensus sites are also the potential binding sites for Pin1, a phosphorylationspecific propyl isomerase never in mitosis gene a (NIMA) 1 (Yaffe et al., 1997). Pin1 is known to regulate the stability of many important MAP kinase substrates, including p53, $\beta$-catenin, and $\mathrm{p} 65$, a nuclear factor $-\kappa \mathrm{B}(\mathrm{NF}-\kappa \mathrm{B})$ subunit, thereby affecting the proliferation of tumor cells (Wulf et al., 2005). In the nervous system Pin 1 action appears to be neuroprotective, blocking tau fibrillization by binding it directly (Lu et al., 1999). The data from Pin $1^{-/-}$mice also support this view, in which the mice develop progressive neuropathy and tau hyperphosphorylation/fibrillization when Pin 1 is deleted (Liou et al., 2002). Recently, however, it has been shown that Pin1 binds BimEL [B-cell lymphoma-2interacting (Bcl-2-interacting) mediator of cell death, extra large] and JNK-interacting protein 3 (JIP3), a neuronal form of JIP, in cultured neurons and promotes apoptosis (Becker and Bonni, 2006). In a spinal cord injury paradigm, on the other hand, we find that Pin 1 plays a mainly anti-apoptotic role, maintaining cytC in the mitochondria in part by binding and stabilizing myeloid cell leukemia sequence-1 (Mcl-1) in the cytosol. Being activated after injury, JNK3 then perturbs this interaction by phosphorylating $\mathrm{Mcl}-1$, thereby promoting its rapid decay and subsequent cytC release.

\section{Materials and Methods}

Construction of plasmids. The Ser ${ }^{121}\left(\mathrm{~S}^{121}\right)$ and $\mathrm{Thr}^{163}\left(\mathrm{~T}^{163}\right)$ residues in Mcl-1 were mutated to Ala (A) individually and together, using a hybrid PCR strategy (Zhong and Bajaj, 1993). The PCR products were placed into a pCR-II vector (Invitrogen, Carlsbad, CA) and sequenced for any errors. The Mcl-1 fragments containing single and double mutations were digested with $\mathrm{KpnI} / \mathrm{Not} \mathrm{I}$ and were used to replace the corresponding fragments in p3XFLAG-CMV-10-Mcl-1. For glutathione $S$-transferaseMcl-1 (GST-Mcl-1) constructs with the wild-type and mutant Mcl-1, the residues from 31 to 229 in Mcl-1 were excised by PCR with BamHI and SalI-containing primers, verified by sequencing, and placed into Bam HI/ SalI sites in pGEX4T1 (Amersham Biosciences, Arlington Heights, IL). For the Pin 1 construct the cDNA was excised from pEGFP-Pin 1 by PCR, using primers with BglII and SalI sites, sequenced, and placed into BglII/ SalI in BamHI/SalI in pGEX4T1.

JNK3 and Pin1 mouse breeding. JNK $3^{+/+}$and $\mathrm{JNK} 3^{-1-}$ mice were obtained from breeding JNK3 ${ }^{+/-}$mice, originally generated in Dr. Richard Flavell's laboratory. The genotype was determined by PCR. Pin $1^{+/+}$ and Pin $1^{-/-}$mice also were obtained from breeding Pin $1^{+/-}$mice.

Spinal cord injury and processing of the cord. Mice were anesthetized with ketamine/xylazine and subjected to hemisection at the thoracic 8-9 level, using mini-Vannas scissors. The control laminectomized mice underwent the same procedure, except for the hemisection. All procedures were approved by the Institutional Laboratory Animal Care and Use Committee and followed National Institutes of Health guidelines for the proper use and care of laboratory animals. For the processing of the cord for proteins, a 6-mm-spinal-cord tissue block (3 mm rostral and $3 \mathrm{~mm}$ caudal regions of the injury epicenter) was dissected quickly and frozen in liquid $\mathrm{N} 2$ at the indicated times. The cords were homogenized in a lysis buffer containing the following (in $\mathrm{mm}$ ): 20 Tris, $\mathrm{pH} 8.0,137 \mathrm{NaCl}, 1$ $\mathrm{MgCl}_{2}, 0.5$ EDTA, 10 Na-pyrophosphate, $10 \mathrm{Na}_{2} \mathrm{P}_{2} \mathrm{O}_{7}, 10 \mathrm{NaF}, 1$ vanadate, 1 phenylmethylfulfonyl fluoride, plus $1 \%$ NP- $40,1 \mu \mathrm{g} / \mathrm{ml}$ aprotinin, $10 \mu \mathrm{g} / \mathrm{ml}$ leupeptin, and $10 \%$ glycerol. The resulting lysates were used in Western analyses as described below. For processing of the cord for immunohistochemistry, the mice were perfused with 3\% paraformaldehyde in $0.1 \mathrm{~m}$ phosphate buffer transcardially, and a $6 \mathrm{~mm}$ segment of the cord that centered on the injury epicenter was removed and cryoprotected in $20 \%$ sucrose in $0.1 \mathrm{~m}$ phosphate buffer. The spinal cord was cut in the horizontal or coronal plane in $20 \mu \mathrm{m}$ thicknesses and processed for immunostaining.

Terminal deoxynucleotidyl transferase-mediated biotinylated UTP nick end labeling and quantification. For terminal deoxynucleotidyl transferase-mediated biotinylated UTP nick end labeling (TUNEL) assays a $6 \mathrm{~mm}$ segment of the cord that centered on the injury epicenter was cut in $20 \mu \mathrm{m}$ thicknesses in the coronal plane and mounted onto slides that were precoated with $0.15 \%$ gelatin and $0.2 \mathrm{mg} / \mathrm{ml}$ poly-D-lysine. To access the nuclei for TUNEL labeling, we boiled the sections in Antigen Retrieval Citra solution (BioGenex, San Ramon, CA) for 2 min at full power and for $15 \mathrm{~min}$ at $10 \%$ power, using a microwave oven. TUNEL reaction was performed by using the Roche (Palo Alto, CA) TUNEL kit and were counterstained for oligodendrocytes and neurons. For quantification, every fourth section was processed and counted.

JNK immunoprecipitation/kinase assays. At the indicated times the spinal cord lysates were prepared and subjected to immunoprecipitation, using JNK1/2 and JNK3 antibodies. The immune complexes were used in kinase reactions with ${ }^{32} \mathrm{P}$ - $\gamma$-ATP in the presence of GST-c-Jun as an exogenous substrate. The kinase reaction was separated on SDS-PAGE and autoradiographed.

Immunoprecipitation/kinase assays. The lysates from the spinal cord or 293 T cells were subjected to immunoprecipitation with appropriate antibodies, and the immune complexes were used in in vitro kinase assays as described in the JNK procedure, except that GST-Mcl-1 wild-type and mutant proteins were used as substrates.

Mitochondrial fractionation. Mitochondria were prepared by sucrose density gradients (Marchenko et al., 2000; Liu et al., 2004). Briefly, the 6-mm-spinal-cord tissue blocs were homogenized by using a Dounce 
A

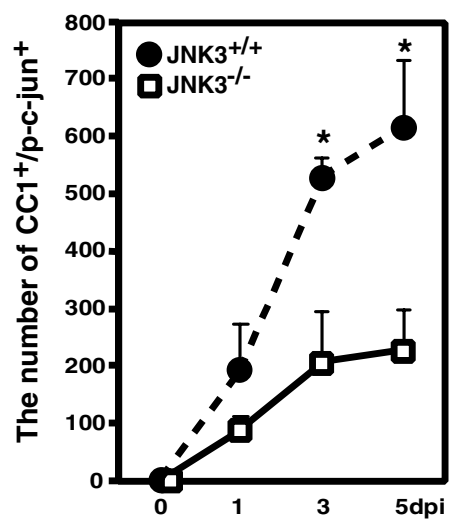

C

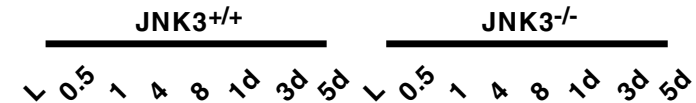

B
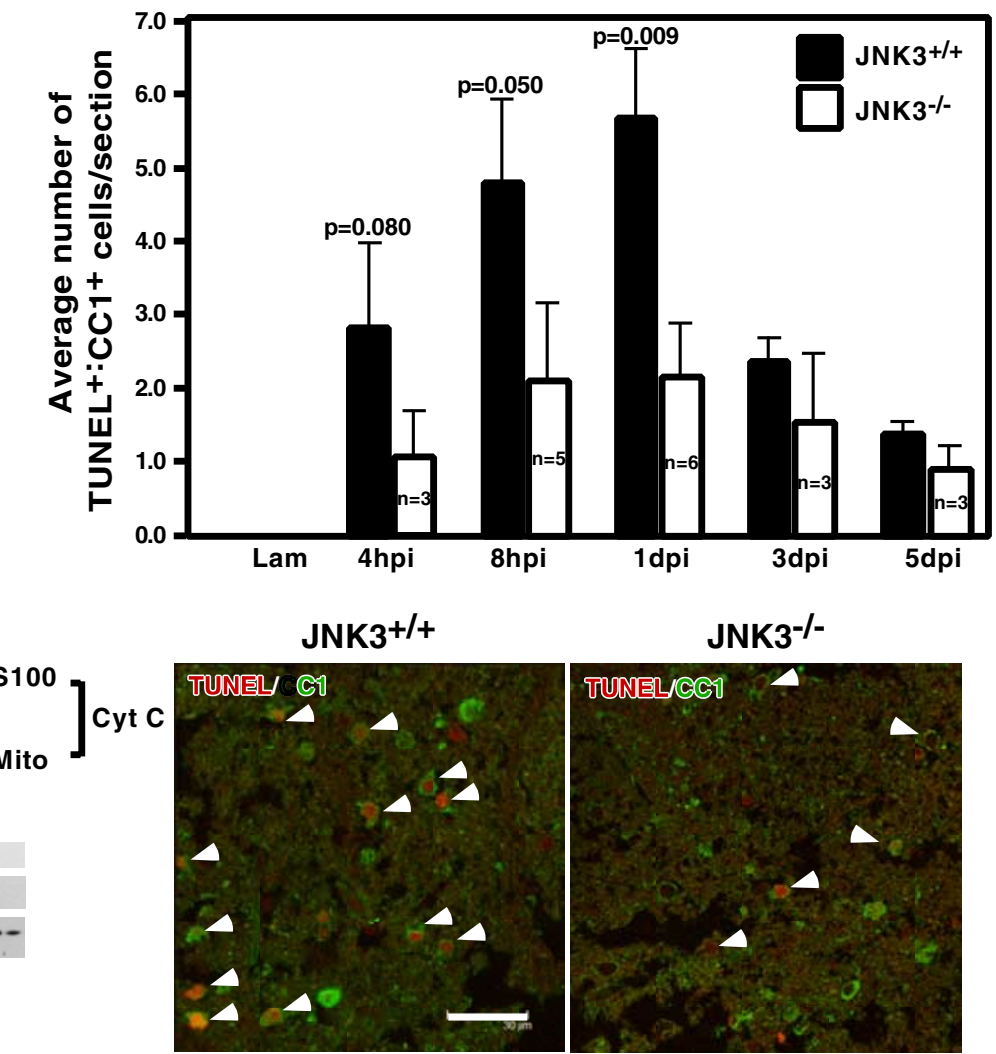

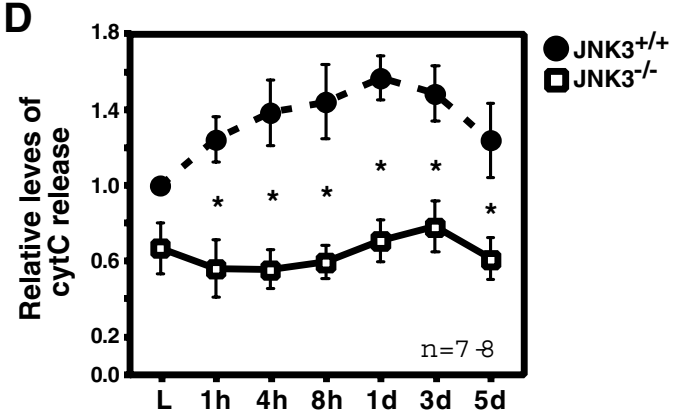

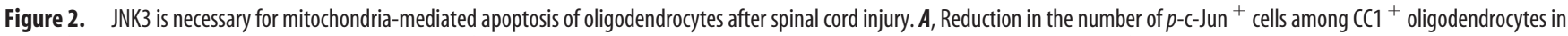
JNK3 $^{-1-}$ mice as compared with the number in JNK3 ${ }^{+/+}$mice. $p$-c-Jun immunoreactivity among $\mathrm{CC}^{+}{ }^{+}$cells was quantified in JNK3 ${ }^{+/+}$and JNK3 ${ }^{-1-}$ mice. The error bars represent SEM. Asterisks represent the time points at which the two genotypes showed statistical difference (Student's $t$ test, $p<0.05$ ). $\boldsymbol{B}$, Top, 0ligodendrocyte apoptosis after spinal cord injury is attenuated in JNK3 $^{-1-}$ mice compared with JNK3 ${ }^{+/+}$mice. Adult JNK3 ${ }^{+/+}$and JNK3 ${ }^{-1-}$ mice were subjected to T9 hemisection. At the indicated time every fourth coronal section was processed for TUNEL and CC1 immunostaining; cells that were positive for both stainings were counted ( $p$ values, Student's $t$ test). The error bars represent SEM. B, Bottom, A representative picture of TUNEL ${ }^{+} / C C{ }^{+}$ cells. Arrowheads point to TUNEL ${ }^{+} / \mathrm{CC}^{+}{ }^{+}$cells. Scale bar, $30 \mu \mathrm{m}$. C, Top, JNK3 is necessary for cytC release from the mitochondria after spinal cord injury. The spinal cord lysates were processed for mitochondrial fractionation by using sucrose gradients. C, Bottom, As controls for fractionation, the mitochondrial, S100, and nuclear fractions were analyzed in a Western blot with a mitochondrial marker, COX-IV, a cytosolic marker, RhoGDI, and a nuclear marker, C-Jun. D, Quantification of the cytC levels in the S100 fraction from JNK3 ${ }^{+/+}$and JNK3 ${ }^{-/-}$mice. Asterisks represent the time points at which the two genotypes showed statistical difference (Student's $t$ test; $p<0.02$ ).

homogenizer in $5 \mathrm{vol}$ of MS buffer as follows (in mM): 210 mannitol, 70 sucrose, 5 EDTA, 5 Tris, $\mathrm{pH} 7.5,10 \mathrm{NaF}, 1$ vanadate, 1 phenylmethylfulfonyl fluoride, plus $1 \mu \mathrm{g} / \mathrm{ml}$ aprotinin, $10 \mu \mathrm{g} / \mathrm{ml}$ leupeptin. Nuclei were collected after centrifugation at $2500 \mathrm{rpm}$ for $10 \mathrm{~min}$ at $4^{\circ} \mathrm{C}$, and the resulting supernatants were spun at $15,000 \mathrm{rpm}$ for $10 \mathrm{~min}$ at $4^{\circ} \mathrm{C}$. The supernatants were subjected to a $1 \mathrm{~h}$ spin at $100,000 \times g$ to obtain the S100 fraction while the crude mitochondrial pellet was resuspended in MS buffer and overlaid onto a step gradient of 1 and $1.5 \mathrm{M}$ sucrose. The gradient was centrifuged for $30 \mathrm{~min}$ at $85,000 \times g$. The mitochondrial band at the interface was pulled, diluted in 2 vol of MS buffer, and spun for $10 \mathrm{~min}$ at $15,000 \mathrm{rpm}$.

Immunoprecipitation/Western blot analyses. The procedures for Western blot analyses are as described previously (Beattie et al., 2002). The antibodies used in the study include JNK1, cytochrome $c$, mouse Mcl-1 (PharMingen, San Diego, CA), JNK2, rabbit Mcl-1, ubiquitin, actin, Bcl2 -associated $\mathrm{X}$ protein (Bax), and Bcl-2 homology-interacting domain death agonist (Bid; Santa Cruz Biotechnology, Santa Cruz, CA), polyposis coli clone 1 (CC1; Oncogene Science, Uniondale, NY), Pin1, $p$-c-Jun (S63), c-Jun, Bcl-xL, $p$-Thr-Pro, $p$-GSK-3 $\beta$, and active caspase 3 (Cell Signaling Technology, Beverly, MA), hemagglutinin (HA; Covance, Princeton, NJ), neuronal marker (NeuN; Chemicon, Temecula, CA), cytochrome $c$ oxidase (COX-IV; Invitrogen), and Flag and Rho GDP dissociation inhibitor (RhoGDI; Sigma, St. Louis, MO).

Phospho-S $S^{121}$-specific Mcl-1 antibody production. The sequence of the phospho-peptide used to generate phospho- $S^{121}$-Mcl-1 antibody was EEMAASAAAAIV(pS)PEEELDGCEPEAIG. The peptide was synthesized by Tufts University Core Facility, coupled to keyhole hemocyanin, and injected into rabbits at Pocono Rabbit Farm (Canadensis, PA). Serum was affinity purified by SulfoLink coupling gel (Pierce, Rockford, IL) to which the phospho-peptide was coupled.

Two-dimensional electrophoresis. The lysates either were untreated or were treated with calf intestinal phosphatase (CIP) at $37^{\circ} \mathrm{C}$ for $1 \mathrm{~h}$ and 
were subjected to dialysis in a buffer containing $8 \mathrm{~m}$ urea, 2\% CHAPS (3-[(3-cholamidopropyl)dimethylammonio]-1-propanesulfonate), and $2 \mathrm{~mm}$ tributyl phosphine. The dialyzed lysates were concentrated by Centricon. At Ohio State Plant Microbe Genomic Facility 20 $\mu \mathrm{g}$ of the protein was loaded onto an immobilized $\mathrm{pH}$ gradient strip, $\mathrm{pH}$ 3-10 (Bio-Rad, Hercules, CA), on the first dimension and additionally resolved at the second dimension in a $8-16 \%$ gradient gel. After electrophoresis the proteins were transferred and probed for Mcl-1 as described (Beattie et al., 2002).

Immunohistochemistry. The procedures for immunohistochemistry were as described previously (Kim et al., 2003).

\section{Results}

JNK3 activity is induced after spinal cord injury and plays a critical role in oligodendrocyte apoptosis

To address whether JNK3 activity itself is regulated under pathological conditions, we established a standard set of conditions, based on spinal cord injury. Mice were subjected to either laminectomy (control) or lateral hemisection at thoracic level 8-9 as reported previously (Beattie et al., 2002), and lysates were prepared at suitable intervals. To measure JNK3 activity specifically, we performed immunoprecipitation/kinase reactions by using JNK3specific antibody (JNK3 antibody fails to detect proteins from $\mathrm{JNK}^{-1-}$ mice) (supplemental Fig. $1 A$, available at www. jneurosci.org as supplemental material). JNK1/2 activities also were measured in parallel by using JNK1/2 antibodies in immunoprecipitation/kinase assays. Beginning $1 \mathrm{~h}$ after injury, we detected a 3- to 3.5-fold increase in JNK3 activity, which was sustained in a prolonged manner until several days after injury (Fig. $1 A, B)$. The JNK1/2 activities showed a transient increase at $1-4 \mathrm{~h}$ time points, but their peak activities were 500-fold lower than that of JNK3 (Fig. 1) (supplemental Fig. $1 B$, available at www. jneurosci.org as supplemental material), suggesting that JNK3 is the major kinase for which the activity is regulated in a prolonged manner after spinal cord injury.

We next asked which types of cells activate JNK in vivo by performing immunohistochemistry with $p$-c-Jun ${ }^{\mathrm{S} 63}$ antibody and cell type-specific antibodies. $p$-c-Jun immunoreactivity was not detected in the control mice, but beginning $1 \mathrm{~d}$ after injury (dpi), it was detected mainly among $\mathrm{NeuN}^{+}$neurons in the gray matter and $\mathrm{CC}^{+}{ }^{+}$oligodendrocytes in the white matter (Fig. 1C). p-c-Jun immunoreactivity was not detected among GFAP ${ }^{+}$astrocytes or $\mathrm{OX} 42^{+}$microglia, and the c-Jun immunoreactivity was detected at the same extent in both the control and injured mice (data not shown). Quantification demonstrates that the number of $p$-c-Jun ${ }^{+}$cells increased over time both among $\mathrm{NeuN}^{+}$and $\mathrm{CCl}^{+}$cells (Fig. $2 \mathrm{~A}$ ) (supplemental Fig. $2 \mathrm{~A}$, available at www.jneurosci.org as supplemental material). The number of $p$-c-Jun ${ }^{+} / \mathrm{CC}{ }^{+}$cells, however, dropped by threefold in JNK3 ${ }^{-1-}$ as compared with that in JNK3 ${ }^{+/+}$mice (Fig. $2 A$, asterisks) ( $p=0.02$ and 0.01 at 3 and 5 dpi, respectively; Student's $t$ test; $n=3$ ), suggesting that JNK3 is the major kinase that is activated and phosphorylating c-Jun after injury among oligodendrocytes. The number of $p$-c-Jun ${ }^{+} / \mathrm{NeuN}^{+}$cells also de-
B

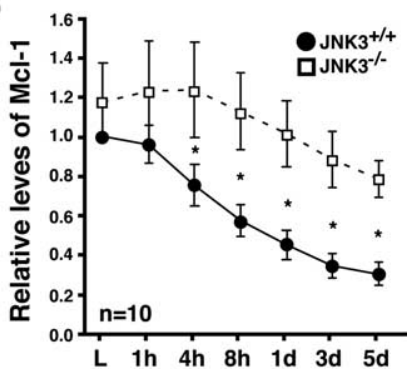

D

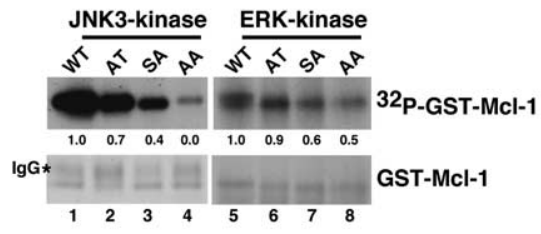

Figure 3. JNK3 regulates $\mathrm{MCl}-1$ stability after injury. $\boldsymbol{A}, \mathrm{Mcl}-1$ protein levels change most dramatically beginning $4 \mathrm{~h}$ after injury mice, coinciding with cytC release. In JNK3 mice, the Mcl-1 levels remain elevated. Actin control is shown; the

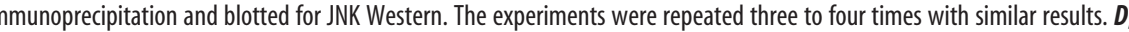
amount of GST-Mcl-1 protein in each lane as Coomassie-stained controls. The asterisk in the stained gel represents lgG. The experiments were repeated three to four times with similar results.

creased in $\mathrm{JNK} 3^{-1-}$, but the difference between $\mathrm{JNK} 3^{-1-}$ and $\mathrm{JNK}^{+/+}$mice was not statistically significant (supplemental Fig. $2 A$, available at www.jneurosci.org as supplemental material).

Oligodendrocytes previously were reported to undergo apoptosis after spinal cord injury in rodents as well as in monkeys (Crowe et al., 1997), typically resulting in 50\% loss of oligodendrocytes (Beattie et al., 2002). We therefore asked whether JNK3 played a role in oligodendrocyte apoptosis by quantifying the number of TUNEL ${ }^{+}$apoptotic oligodendrocytes. The number of $\mathrm{TUNEL}^{+}$cells among $\mathrm{CC} 1^{+}$cells decreased by twofold to threefold in $\mathrm{JNK}^{-1-}$ mice as compared with $\mathrm{JNK} 3^{+/+}$littermates (Fig. $2 B$ ), whereas the number of TUNEL ${ }^{+} / \mathrm{NeuN}^{+}$cells did not differ greatly between the two genotypes (supplemental Fig. $2 B$, available at www.jneurosci.org as supplemental material). The total JNK protein levels did not vary significantly between $\mathrm{JNK}^{-/-}$and JNK3 ${ }^{+/+}$mice (supplemental Fig. $1 A$, available at www.jneurosci.org as supplemental material), in agreement with a previous report (Kuan et al., 2003). These results suggest that JNK3 is the key kinase for which activation plays a critical role in the injury-induced apoptosis of oligodendrocytes.

\section{JNK3 is necessary for cytochrome $c$ release}

JNK1 and JNK2 were shown to induce cytC release from the mitochondria in embryonic fibroblast cultures after UV irradiation (Tournier et al., 2000). We therefore tested whether cytC was released after injury and whether JNK3 regulated cytC release. For these experiments the injury lysates were subjected to a sucrose gradient to isolate the pure mitochondrial fraction (Marchenko et al., 2000; Liu et al., 2004). In parallel, S100 and nuclear fractions were prepared also. The purity of each fraction obtained in a typical fractionation is demonstrated in Figure $2 C$ (bottom panel). In $\mathrm{JNK}^{+/+}$mice cytC was released into the $\mathrm{S} 100$ fraction with a concomitant decrease occurring in the mitochondria be- 
ginning $4 \mathrm{~h}$ after injury (Fig. 2C), a time course that is notably similar to what has been reported in various in vitro studies (Nijhawan et al., 2003). In contrast, cytC release was reduced significantly in $\mathrm{JNK}^{-1-}$ mice (Fig. 2C,D). These results suggest that JNK3 activity is involved in regulating injury-mediated cytC release, the initial step that is necessary for activating the caspase cascade (Liu et al., 1996).

JNK3 is necessary for injury-induced degradation of Mcl-1

Because the Bcl-2 family members are involved in regulating cytC release from the mitochondria (Gross et al., 1999), we screened for the Bcl-2 family member for which the expression is regulated by JNK3 and for which the expression levels also change in accordance with cytC release kinetics. Of the Bcl-2 family members that were screened (supplemental Fig. 3, available at www.jneurosci.org as supplemental material), Mcl-1 and Bcl-2 fit both criteria. Of the two anti-apoptotic Bcl-2 family members, Mcl-1 recently was reported as the critical cytosolic inhibitor having a short $40 \mathrm{~min}$ half-life, which regulates cytC release from the mitochondria under various apoptotic stimuli (Nijhawan et al., 2003; Zhong et al., 2005). Increasing Mcl-1 levels experimentally blocked cytC release after UV irradiation (Nijhawan et al., 2003), and inhibiting Mcl-1 ubiquitination by downregulating its ubiquitin ligase E3 (Mule) also resulted in increased cell survival when DNA-damaging agents were applied to cells (Zhong et al., 2005). These results suggest that the degradation of $\mathrm{Mcl}-1$ is a prerequisite for cytC release and subsequent activation of the caspase cascade (Nijhawan et al., 2003). We therefore focused on $\mathrm{Mcl}-1$ as a potential substrate for JNK3 that can regulate cytC release. In agreement with these culture data, Mcl-1 protein levels began to decrease $4 \mathrm{~h}$ after spinal cord injury in $\mathrm{JNK}^{+/+}$mice, which coincides in a time-lapse period with the initial cytC release (Fig. $3 A, B$ ). In JNK3 ${ }^{-1-}$ mice, however, Mcl-1 protein levels remained significantly elevated when compared with those in the wild type (Fig. $3 A, B$ ), suggesting that JNK3 regulates $\mathrm{Mcl}-1$ stability.

\section{JNK3 phosphorylates Mcl-1 at $\mathrm{S}^{121}$ after injury}

Mcl-1 has two MAP kinase phosphorylation sites, $\mathrm{S}^{121} \mathrm{P}$ and $\mathrm{T}^{163} \mathrm{P}$. It was shown in culture that extracellular signal-regulated kinase (ERK) phosphorylates Mcl-1 at $\mathrm{T}^{163} \mathrm{P}$ in the basal state (Domina et al., 2004) and JNK phosphorylates Mcl-1 at $\mathrm{S}^{121}$ and $\mathrm{T}^{163}$ in response to $\mathrm{H}_{2} \mathrm{O}_{2}$ treatment (Inoshita et al., 2002). In agreement with these data, we found that Mcl-1 can be phosphorylated by ERK as well as by $\mathrm{p} 38$, JNK1, and JNK3 in vitro (supplemental Fig. $4 A$, available at www.jneurosci.org as supplemental material). Of these MAP kinases, JNK and ERK are the only ones
B

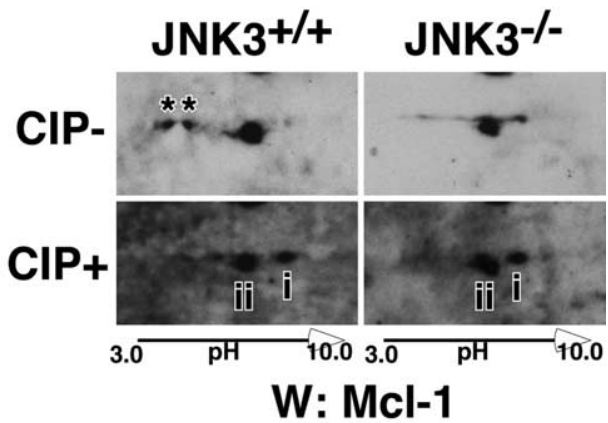

D

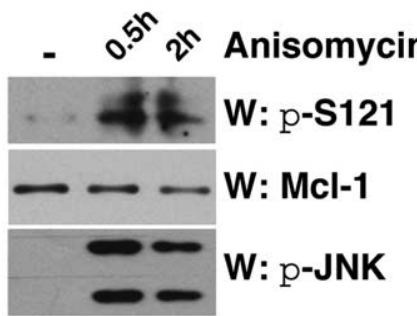

E

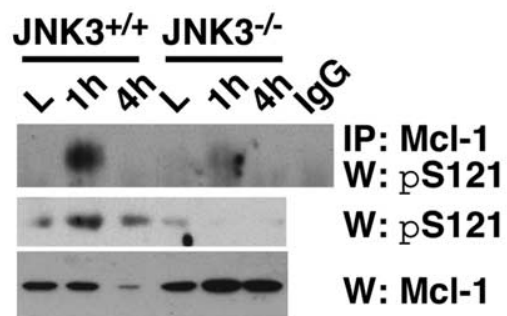

W: $\mathrm{p}-\mathrm{S121}$

W: p-JNK

W: p-JNK

Figure 4. JNK3 phosphorylates MCl-1 at $S^{121}$ in vivo after injury. $A, M C l-1$ was phosphorylated at $\mathrm{T}^{163} \mathrm{P}$ in the uninjured spinal antibody and probed in a Western blot with $p$ Thr-Pro antibody. The same blot was stripped and reprobed for Mcl-1 as a control. $\boldsymbol{B}_{\text {, }}$

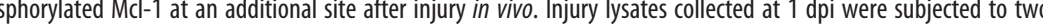

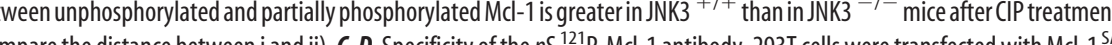
and Mcl- ${ }^{\text {AT }}$ mutants $(\boldsymbol{C})$ or not (D). To phosphorylate the endogenous Mcl-1 or the mutants, we treated $293 \mathrm{~T}$ cells with $50 \mathrm{ng} / \mathrm{ml}$ anisomycin for $30 \mathrm{~min}$ or $2 \mathrm{~h}$. To inhibit degradation of phosphorylated Mcl-1, we also added $10 \mu \mathrm{M}$ MG132 to cells before anisomycin treatment. Note that $p \mathrm{~S}^{121} \mathrm{P}-\mathrm{MCl}-1$ antibody detected $\mathrm{Mcl}-1^{\mathrm{SA}}$, but not the $\mathrm{MCl}-1^{\mathrm{AT}}$ mutant, and only when JNK was ( $\boldsymbol{C}$ and, similarly, the endogenous Mcl-1 only after anisomycin treatment $(\boldsymbol{D})$. $\boldsymbol{E}$, JNK3 phosphorylated Mcl-1 at $S^{121}$ Westerns with the $p S^{121} \mathrm{P}-\mathrm{Mcl}-1$ antibody. As controls, direct Western blots with $p S^{121} \mathrm{P}-\mathrm{Mcl}-1$ and $\mathrm{MCl}-1$ antibodies also are shown. All of the experiments were repeated two to three times with similar results.

for which the activities become induced after spinal cord injury; the peak JNK1/2 activity is very low, the activation is transient, and p38 activity does not increase with injury until 3 dpi (supplemental Figs. 1, 4B, available at www.jneurosci.org as supplemental material). It should be pointed out that, although both JNK3 and ERK activities are induced by injury, ERK differs from JNK3 by remaining active in the basal state without injury, based on p-ERK/ERK Westerns (supplemental Fig. 4C, available at www. jneurosci.org as supplemental material). Among JNK proteins JNK1 and JNK3 appear to phosphorylate Mcl-1 better than JNK2, at least in vitro (Fig. 3C).

We next determined which of the two sites is phosphorylated by ERK and JNK3 in vitro and in vivo. For in vitro experiments 293 T cells were treated with epidermal growth factor (EGF) or transfected with JNK3 cDNA, and the resulting lysates were subjected to immunoprecipitation/kinase reactions by using GST- 
A

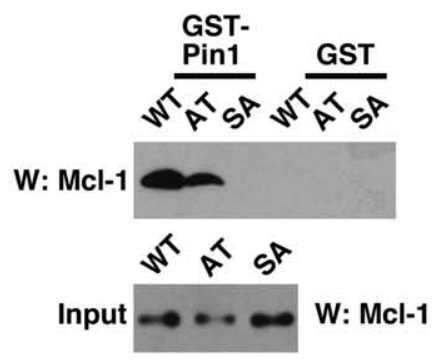

B

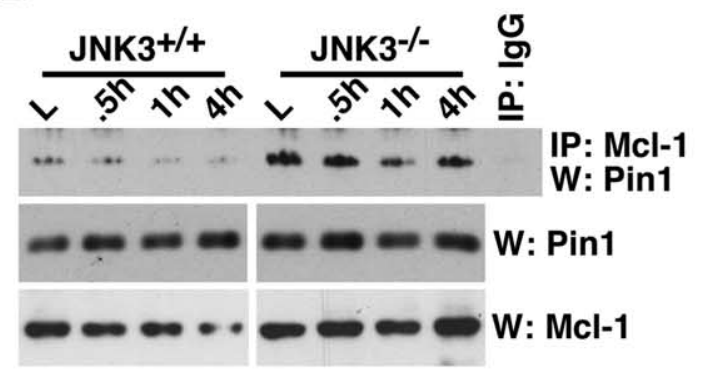

C

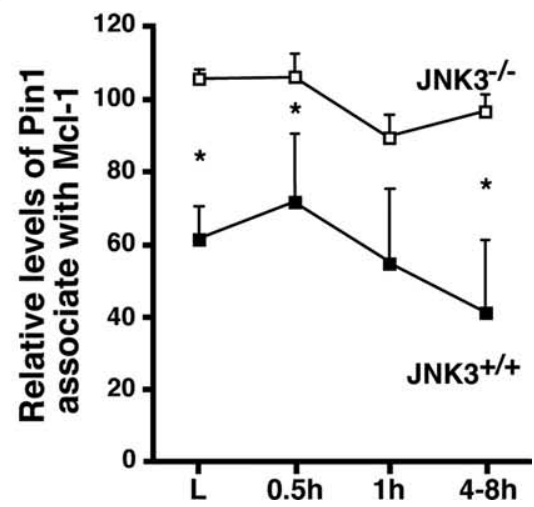

Figure 5. Pin 1 binding to Mcl-1 inhibits ubiquitination and degradation of Mcl-1. A, Pin 1 binds Mcl-1 at $T^{163} \mathrm{P}$. $293 \mathrm{~T}$ cells were transfected with Mcl-1 wild type and mutants and were treated with $50 \mathrm{ng} / \mathrm{ml}$ anisomycin for $30 \mathrm{~min}$ to activate the endogenous JNK pathway. Lysates then were subjected to pulldown assays with GST or GST-Pin1. The Mcl-1 input controls are shown also. B, Pin 1 binds MCl-1 in vivo, and its binding to MCl-1 decreases with injury more rapidly in the wild-type mice as compared with JNK3 ${ }^{-1-}$ mice. The lysates were immunoprecipitated with Mcl-1 or the control lgG, and the bound Pin 1 was probed. The levels of Pin 1 and Mcl- 1 are shown as controls. C, Quantification of the amount of Pin 1 bound to Mcl- $1(n=3)$. Asterisks represent the time points at which the two genotypes showed a statistical difference (Student's $t$ test, $p<0.05$ ). The difference at $1 \mathrm{~h}$ after injury was $p=0.08$ (Student's $t$ test).

Mcl-1-S ${ }^{121} \mathrm{~A}(\mathrm{AT}), \mathrm{T}^{163} \mathrm{~A}(\mathrm{SA})$, and $\mathrm{S}^{121} \mathrm{~A} / \mathrm{T}^{163} \mathrm{~A}(\mathrm{AA})$ mutants in addition to $\mathrm{Mcl}-1^{\mathrm{wt}}$ (wild type) as substrates. The results indicate that JNK3 phosphorylates Mcl-1 at both $\mathrm{S}^{121} \mathrm{P}$ and $\mathrm{T}^{163} \mathrm{P}$ sites, whereas ERK mainly phosphorylates $\mathrm{T}^{163}$ (Fig. 3C). The observation that ERK preferentially phosphorylates Mcl-1 at $\mathrm{T}^{163} \mathrm{P}$ and that ERK remains active in the spinal cord without injury suggests that Mcl-1 should remain phosphorylated at that site in the basal state. Indeed, Mcl-1 was found to be phosphorylated at $\mathrm{T}^{163} \mathrm{P}$ in the uninjured spinal cord, based on the $p \mathrm{~T}$ $\mathrm{P}$-specific immunoreactivity detected from the immunoprecipitated Mcl-1 (Fig. 4A). This basal phosphorylation was independent of the JNK3 genotype. These data together suggest that ERK is most likely to be responsible for phosphorylating Mcl-1 in the basal state, in agreement with the published data from culture studies (Inoshita et al., 2002; Domina et al., 2004). It also should be noted that $p \mathrm{~T}^{163} \mathrm{P}$ recently was discovered to be a part of a glycogen synthase kinase (GSK) target site, $\mathrm{S}^{159}$ LPST $^{163}$, where T typically remains constitutively phosphorylated as a priming site for GSK, which phosphorylates Mcl-1 at $S^{159}$ (Cohen and Frame, 2001; Maurer et al., 2006).

Because JNK3 is necessary for Mcl-1 degradation after injury, we believed it was highly likely that JNK3 is responsible for phosphorylating $\mathrm{Mcl}-1$ at $\mathrm{S}^{121} \mathrm{P}$ after injury in vivo. Two different approaches were taken to address whether JNK3 phosphorylates Mcl-1 at $\mathrm{S}^{121} \mathrm{P}$ after injury. First, in Western analyses of the injured lysates after two-dimensional gel electrophoresis, Mcl-1 protein yielded two additional phosphorylated bands in $\mathrm{JNK}^{+/+}$, but not in JNK3 ${ }^{-1-}$ (Fig. $4 B$, two asterisks), suggesting that $\mathrm{Mcl}-1$ is phosphorylated in a greater degree in $\mathrm{JNK}^{+1+}$ than in JNK3 ${ }^{-1-}$ mice. In agreement with these data, a CIP treatment of the same lysates revealed that the distance between unphosphorylated Mcl-1 (Fig. 4B, band i) and the partially phosphorylated Mcl-1 (Fig. $4 B$, band ii) is greater in JNK3 ${ }^{+/+}$when compared with that in $\mathrm{JNK}^{-1-}$. These data together suggest that Mcl-1 phosphorylation is attenuated in the absence of JNK3.

For the second approach we generated a phosphorylationspecific antibody against the peptide sequence around $p S^{121} \mathrm{P}$ in Mcl-1 (the peptide sequences are shown in Materials and Methods). The antibody detected Mcl-1 only when $S^{121}$ was phosphorylated in vitro (Fig. $4 C, D$ ), suggesting that the antibody is indeed specific to $p S^{121}-\mathrm{Mcl}-1$. We next subjected the injury lysates to immunoprecipitation with Mcl-1 antibody and Westerns with the $p S^{121}$-Mcl-1 antibody. The intensity of $p S^{121}$-specific immunoreactivity increased at $1 \mathrm{~h}$ after injury in JNK3 ${ }^{+/+}$, whereas it was reduced significantly in JNK3 ${ }^{-1-}$ mice (Fig. $4 E$ ). A similar increase in $p S^{121}$-specific signal from the wild-type but not in the knock-out mice also was observed in a direct Western with the $p S^{121}$-specific antibody (Fig. $4 E$ ). These results together suggest that JNK3 phosphorylates $\mathrm{Mcl}-1$ at $\mathrm{S}^{121}$ after spinal cord injury in vivo.

Mcl-1 recently was reported to be phosphorylated by GSK at the time of interleukin-3 withdrawal in culture (Maurer et al., 2006). We, on the other hand, found that GSK-3 activities decrease with injury independently of the JNK3 genotype (supplemental Fig. 5, available at www.jneurosci.org as supplemental material). We interpret these results as suggesting that GSK is not likely to participate in Mcl-1 phosphorylation/ubiquitination in the spinal cord. What is regulated by the injury, however, is $\mathrm{S}^{121}$ phosphorylation by JNK3, and this phosphorylation is critical for $\mathrm{Mcl}-1$ stability in vivo.

\section{Mcl-1 recruits Pin 1 at its constitutively phosphorylated site $\mathrm{T}^{163} \mathrm{P}$}

The phosphorylation sites in $\mathrm{Mcl}-1, \mathrm{~S}^{121} \mathrm{P}$ and $\mathrm{T}^{163} \mathrm{P}$, are the potential binding sites for Pin1, a phosphorylation-specific propyl isomerase (Yaffe et al., 1997). We therefore addressed whether Pin 1 is involved in regulating Mcl-1 stability after injury, first by examining whether Pin 1 binds Mcl-1 and which of the two putative sites is involved, using two Mcl-1 mutants, $\mathrm{S}^{121} \mathrm{~A}$ (AT) and $\mathrm{T}^{163} \mathrm{~A}(\mathrm{SA})$. To facilitate the phosphorylation of $\mathrm{S}^{121} \mathrm{P}$ and $\mathrm{T}^{163} \mathrm{P}$, we transfected $293 \mathrm{~T}$ cells with the Mcl-1 wild type and mutants, and we treated them with $50 \mathrm{ng} / \mathrm{ml}$ anisomycin for 30 min to activate the endogenous JNK1/2. In subsequent GSTPin 1 pulldown assays, Pin 1 bound $\mathrm{Mcl}-1$ at $p \mathrm{~T}^{163} \mathrm{P}$ and not $p \mathrm{~S}^{121} \mathrm{P}$ (Fig. 5A). Because Mcl-1 is phosphorylated at $\mathrm{T}^{163} \mathrm{P}$ in the basal state, it could be deduced that Pin 1 must bind Mcl-1 at $p \mathrm{~T}^{163} \mathrm{P}$ in the absence of injury. Indeed, Pin 1 interacted with Mcl-1 in the basal state, and its interaction decreased after injury in the wild-type mice, whereas the extent of its decrease was reduced in JNK3 ${ }^{-1-}$ mice (Fig. $5 B, C$ ). These results suggest that Pin 1 may protect $\mathrm{Mcl}-1$ from being degraded in the absence of injury. 


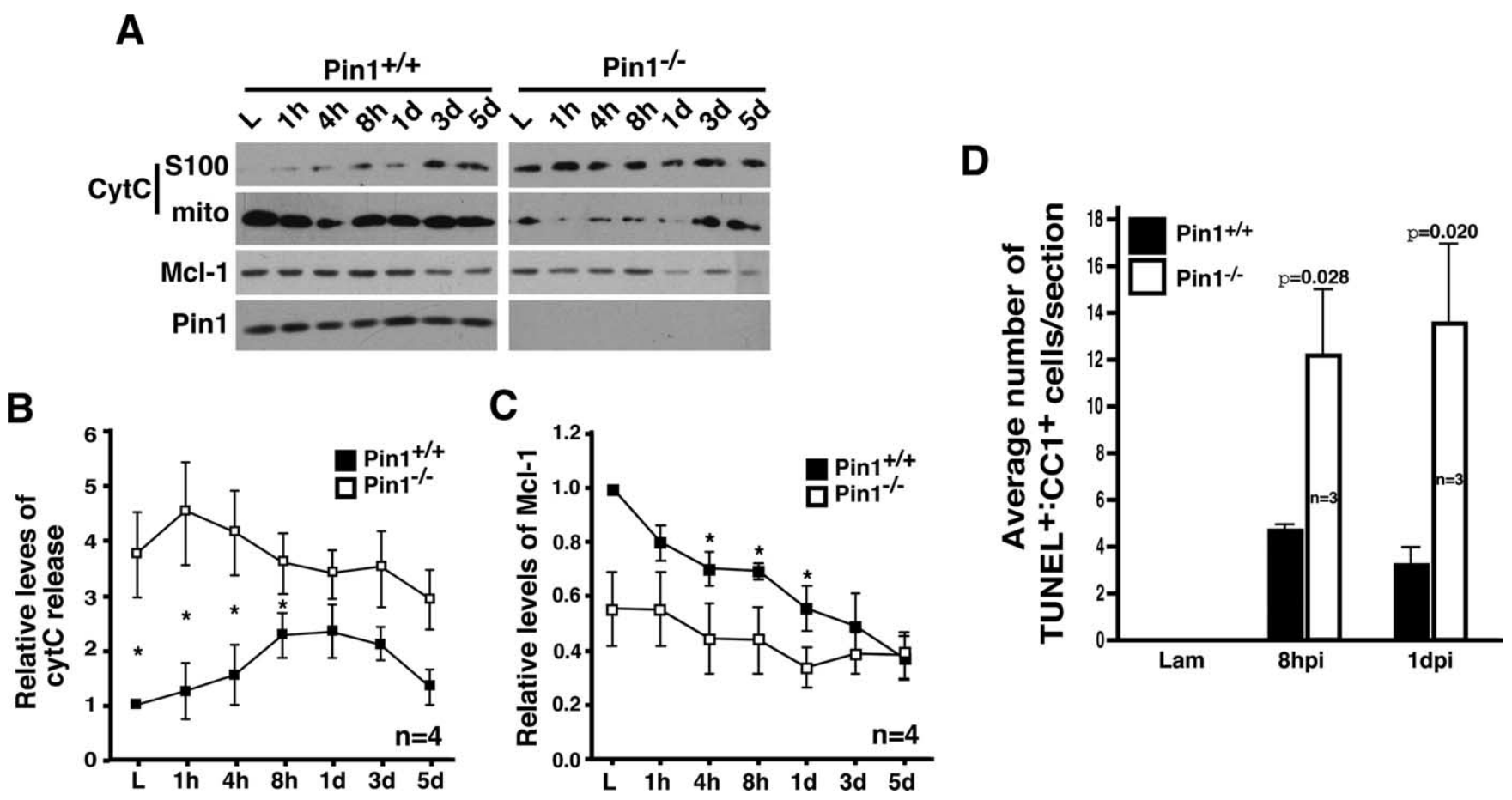

Figure 6. Pin 1 is necessary for inhibiting cytC release, at least in part by regulating Mcl-1 stability in vivo. $A$, CytC not only is released constitutively in the basal state but also increases additionally after injury in Pin $1^{-1-}$ mice. B, Quantification of cytC release at different time points after injury. C, Quantification of the relative Mcl-1 levels at different time points after injury. B, C, Asterisks represent the time points at which the two genotypes showed a statistical difference (Student's test, $p<0.05$ ). $\boldsymbol{D}$, Apoptosis of oligodendrocytes increases in Pin $1^{-1-}$ mice after spinal cord injury. The error bars represent SEM.

A

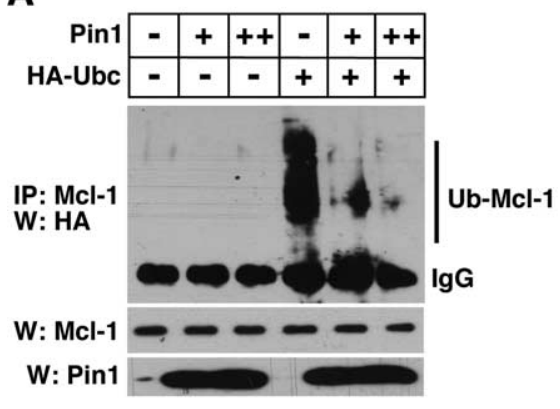

B

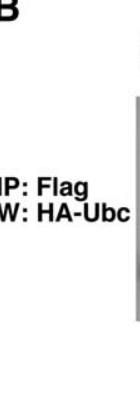

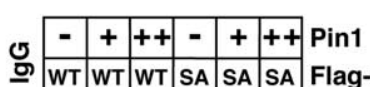

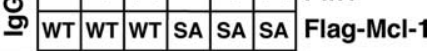

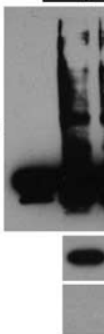

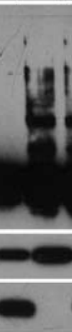

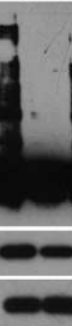

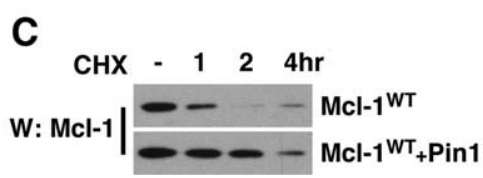

Figure 7. Pin 1 inhibits ubiquitination of Mcl-1. A, Pin 1 inhibits the extent of Mcl-1 ubiquitination in a dose-dependent manner. At $1 \mathrm{~d}$ after transfection, 293T cells were treated with $10 \mu \mathrm{m}$ MG132 to stop Mcl-1 degradation; $6 \mathrm{~h}$ later the lysates were subjected to immunoprecipitation with MCl-1 and probed for ubiquitin with $\mathrm{HA}$ antibody. Ub-Mcl-1 indicates ubiquitinated Mcl-1. As controls, Mcl-1 and Pin 1 Westerns are shown also. B, Pin 1 binding regulates $\mathrm{Mcl}-1$ ubiquitination. The T ${ }^{163} \mathrm{~A}$ mutant that no longer binds Pin 1 becomes ubiquitinated even in the presence of an increasing amount of Pin1. The experiments were performed similarly to those in A. C, Mcl-1 degradation after cycloheximide treatment is delayed in the presence of excess Pin1. 293T cells were transfected with the indicated constructs and treated with $50 \mu \mathrm{g} / \mathrm{ml}$ cycloheximide for the indicated amount of time. All of the experiments were repeated three to four times with similar results.

Pin 1 action is anti-apoptotic in vivo

If the neuroprotective action of Pin 1 includes promoting the stability of $\mathrm{Mcl}-1$, a cytosolic regulator of cytC release, one would expect cytC release to increase in the absence of Pin1, opposite of what we observed in JNK3 $3^{-1-}$ mice. In Pin $1^{-1-}$ mice cytC was released constitutively and remained elevated to levels higher than in the wild type

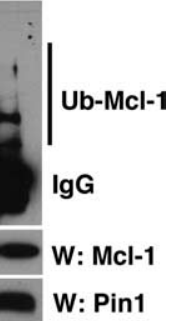

after injury (Fig. 6A,B). In addition, overall Mcl-1 levels were reduced at all time points, but the decay kinetics was similar to that in Pin $1^{+/+}$mice (Fig. $6 A, C$ ). When the apoptotic profile was examined, however, there were no TUNEL $^{+}$cells in the uninjured Pin $1^{-/-}$mice despite the fact that cytC release was constitutive (Fig. 6D). Only with injury, the overall extent of apoptosis increased threefold to fivefold in oligodendrocytes in the absence of Pin1. These results suggest that cytC release alone is not sufficient to induce apoptosis, and an injuryinduced signal is necessary for oligodendrocytes to die. The opposing phenotypes that are observed between $\mathrm{JNK}^{-1-}$ and Pin $1^{-1-}$ mice suggest that JNK3 is at least one of the critical signals that initiate the apoptotic cascade in spinal cord injury models.

\section{Pin1 binding inhibits}

Mcl-1 ubiquitination

We hypothesized that one of the mechanisms by which Pin 1 protects $\mathrm{Mcl}-1$ from degradation is to interfere with $\mathrm{Mcl}-1$ ubiquitination. To test this hypothesis, we transfected 293T cells with increasing amounts of Pin 1 plus HA-Ubc and treated them with benzyloxycarbonyl-leucyl-leucyl-leucinal (MG132), a proteasome inhibitor, to block Mcl-1 degradation after ubiquitination. In the absence of added Pin 1, Mcl-1 underwent ubiquitination, which was attenuated considerably by Pin 1 addition in a dose-dependent manner (Fig. 7A). To test next whether this in- 
hibitory effect was attributable to Pin1 binding to Mcl-1, we transfected the wild-type $\mathrm{Mcl}-1$ or the mutant $\mathrm{Mcl}-1$ in which the Pin 1 binding site, $\mathrm{T}^{163} \mathrm{P}$, was mutated to $\mathrm{A}^{163} \mathrm{P}$ (Fig. $7 B$, SA mu$\operatorname{tant})$. Although the increasing amount of Pin 1 protected the wild-type Mcl-1 from being ubiquitinated, it failed to do so with the $\mathrm{A}^{163} \mathrm{P}$ (SA) mutant (Fig. $7 B$ ). These results together suggest that direct Pin 1 binding protects $\mathrm{Mcl}-1$ from degradation by interfering with its ubiquitination under normal conditions. As predicted from this notion, a simple overexpression of Pin 1 in 293T cells delayed the Mcl-1 decay after cycloheximide treatment (Fig. 7C). Because Pin 1 binds Mcl-1 in vivo via the constitutively phosphorylated $p \mathrm{~T}^{163} \mathrm{P}$ site, we interpret these results as suggesting that JNK3 activity counteracts Pin 1 action toward Mcl-1 as it phosphorylates Mcl-1 at $\mathrm{S}^{121}$ after injury.

\section{JNK3 phosphorylation at $S^{121}$ is necessary for Pin 1 to \\ dissociate from Mcl-1}

What are the mechanisms by which JNK3 counteracts the protective action of Pin 1 ? One of the consequences of $S^{121}$ phosphorylation may be to facilitate Pin 1 to dissociate from Mcl-1. Unleashed from Pin1, Mcl-1 would undergo a conformational shift, which could allow subsequent ubiquitination. Our effort to distinguish Mcl-1 that is phosphorylated at $\mathrm{S}^{121}$ from other forms that are not was difficult in vivo. We therefore turn to $293 \mathrm{~T}$ cells, in which we can ask directly whether JNK3 phosphorylation of $\mathrm{S}^{121}$ is necessary for Pin 1 to dissociate from Mcl-1. If JNK3dependent phosphorylation of $S^{121}$ were indeed necessary for Pin 1 to dissociate, one would expect that rendering $S^{121}$ unavailable for JNK activation would allow Pin to remain bound to Mcl-1. For these experiments $293 \mathrm{~T}$ cells were transfected with Pin 1 plus Mcl- ${ }^{\mathrm{SE}}$ or Mcl- ${ }^{\mathrm{AE}}$ mutants and were subjected to 250 $\mathrm{ng} / \mathrm{ml}$ anisomycin. At this concentration anisomycin not only inhibits protein synthesis but also activates the endogenous JNK pathway, which leads to phosphorylation of both $S^{121}$ and $\mathrm{T}^{163}$ in 293T cells (supplemental Fig. 4A, available at www.jneurosci.org as supplemental material) (data not shown). We also mutated $\mathrm{T}^{163}$ to a pseudo-phosphorylation site, $\mathrm{E}^{163}$, to allow $\mathrm{S}^{121}$ to be the only site being targeted by JNK. After anisomycin treatment the amount of Pin 1 bound to $\mathrm{Mcl}-1^{\mathrm{SE}}$ decreased, whereas the amount of Pin1 bound to Mcl-1 ${ }^{\mathrm{AE}}$ did not (Fig. $8 \mathrm{~A}$ ). Accordingly, the degradation of $\mathrm{Mcl}-1^{\mathrm{AE}}$ was delayed when compared with that of Mcl-1 ${ }^{\mathrm{SE}}$ (Fig. $8 \mathrm{~B}$ ). It should be added that we obtained similar results with $\mathrm{A} / \mathrm{S}^{121} \mathrm{~T}^{163}$ as we did with $\mathrm{A} / \mathrm{S}^{121} \mathrm{E}^{163}$ (data not shown). These results together suggest that $S^{121}$ phosphorylation is necessary for Pin1 to dissociate from Mcl-1.

\section{Discussion}

We report here that JNK3 activation is critical for apoptosis of oligodendrocytes after spinal cord injury. JNK3 activity itself is induced by the injury, regulating cytC release by phosphorylating Mcl-1 at $\mathrm{S}^{121}$, a pro-survival member of the BclII family. The outcome of this phosphorylation is to facilitate proteasomemediated degradation of Mcl-1. Our data suggest that Mcl-1 degradation normally is inhibited in part by Pin 1, which binds Mcl-1 at $p \mathrm{~T}^{163} \mathrm{P}$. Because Pin 1 fails to dissociate from Mcl-1 mutant $\left(\mathrm{S}^{121} \mathrm{~A}\right)$ even after JNK is activated, we conclude that the phosphorylation of Mcl-1 at $\mathrm{S}^{121}$ by JNK3 is necessary for displacing Pin1 from Mcl-1 after injury. Loss of Pin1 leads to Mcl-1 ubiquitination, probably by Mule, and subsequent degradation, which ultimately results in cytC release. In agreement with the protective role of $\mathrm{Pin} 1$, cytC release remains constitutive and apoptosis increases dramatically after injury in Pin $1^{-/-}$mice. A model depicting our data is shown in Figure 9.
A

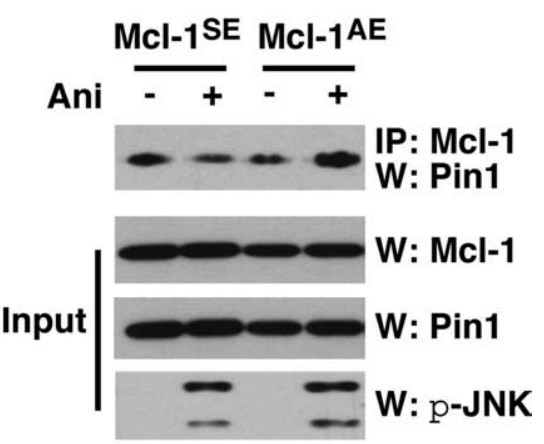

B

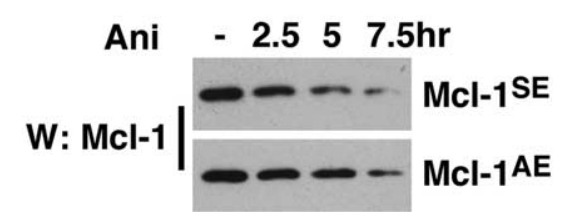

Figure 8. JNK3-dependent phosphorylation of Mcl-1 at $S^{121} \mathrm{P}$ is necessary for Pin1 to dissociate from Mcl-1. A, The Pin 1 binding to $\mathrm{Mcl}-1$ fails to decrease with the $S^{121} \mathrm{~A}$ mutant. Mcl-1 ${ }^{\mathrm{SE}}$ and $\mathrm{Mcl}-1^{\mathrm{AE}}$ mutants were introduced to $293 \mathrm{~T}$ cells, which subsequently were subjected to 250 $\mathrm{ng} / \mathrm{ml}$ anisomycin treatment. Anisomycin blocks protein synthesis and activates JNK at that concentration. The amount of bound Pin1 to Mcl-1 mutants was assessed. Controls for JNK activation after anisomycin treatment are shown as p-JNK Western blots along with $\mathrm{Mcl}-1$ and Pin 1 input controls. $\boldsymbol{B}$, Anisomycin-induced $\mathrm{Mcl}-1$ degradation is delayed in the $\mathrm{Mcl}-1^{\mathrm{AE}}$ mutant when compared with the Mcl-1 ${ }^{\mathrm{SE}}$ mutant. $293 \mathrm{~T}$ cells were transfected with the indicated constructs and treated with $250 \mathrm{ng} / \mathrm{ml}$ anisomycin for the indicated period of time. All of the experiments were repeated four to five times with similar results.

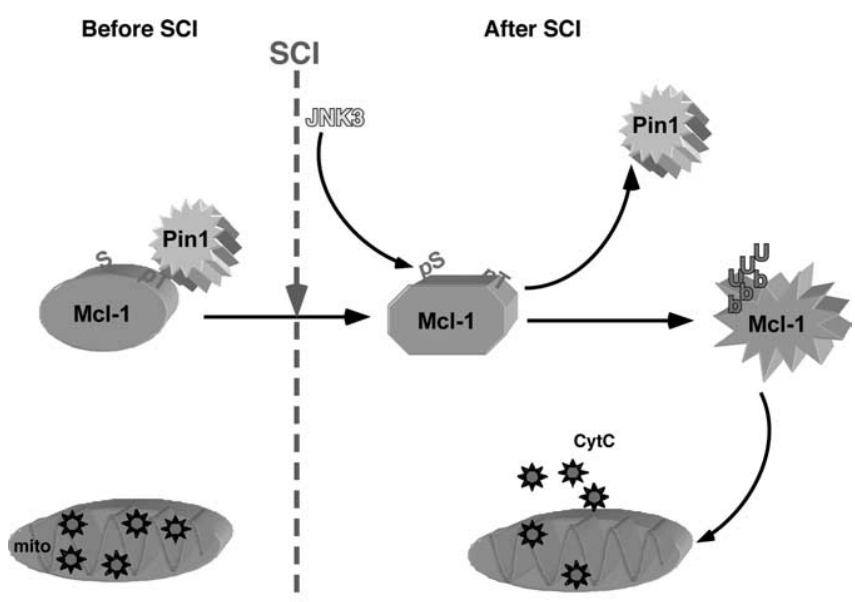

Figure 9. A model of JNK3 action in vivo. In the absence of injury, $\mathrm{Mcl}-1$ is maintained in its phosphorylated state at $\mathrm{T}^{163} \mathrm{P}$, which recruits Pin1 to bind. Pin1 binding inhibits $\mathrm{Mcl}-1$ ubiquitination and degradation. With the Mcl-1 protein level elevated, cytC remains in the mitochondria (mito). With injury (SCl), however, JNK3 is activated and phosphorylates Mcl-1 at $S^{121} \mathrm{P}$, which results in a conformational shift in $\mathrm{Mcl}-1$, thereby facilitating Pin1 to dissociate. With Pin1 removed from $\mathrm{Mcl}-1, \mathrm{Mcl}-1$ undergoes ubiquitination and subsequent degradation. Degradation of $\mathrm{Mcl}-1$ leads to changes in the dynamics of $\mathrm{BCl}-2$ molecule interactions, leading to cytC release into the cytosol.

Activation of the caspase pathways initiated by cytC release is a fundamental aspect of the apoptotic process (Liu et al., 1996), observed in many pathological conditions (Benn and Woolf, 2004). For cytC to be released under pathological stimuli, Mcl-1 
must be degraded (Nijhawan et al., 2003; Maurer et al., 2006). Our results are in agreement with the above report; when Mcl-1 levels were elevated in JNK3 ${ }^{-1-}$ mice, cytC release was attenuated and oligodendrocyte survival was enhanced. The mechanism by which Mcl-1 stability is regulated, however, has remained unknown, except for the fact that it is ubiquitinated (Zhong et al., 2005). Here, we document that Pin 1 is involved in maintaining Mcl-1 stability by inhibiting its ubiquitination. Without Pin 1 the $\mathrm{Mcl}-1$ levels were reduced, and cytC release remained constitutive in the absence of injury.

As a phosphorylation-specific propyl isomerase, Pin 1 regulates the protein turnover of some of the key transcriptional factors that are critical for proliferation as well as cytosolic proteins, such as tau, that are involved in neurodegeneration (Wulf et al., 2005). Indeed, Pin $1^{-1-}$ mice develop tau filament formation over time (Liou et al., 2003), suggesting that Pin1 in the cytosol plays a pro-survival function in the CNS. Our results here provide the evidence for an additional mechanism by which Pin 1 acts to promote cell survival in the cytoplasm, that is, via maintaining normal mitochondrial homeostasis by protecting $\mathrm{Mcl}-1$ from being ubiquitinated and degraded unless an apoptotic signal is initiated. Because mitochondrial dysfunction is observed in many of the neurodegenerative diseases, it is tempting to speculate that a similar opposite regulation between JNK3 and Pin1 plays a role toward maintaining mitochondrial homeostasis.

It was surprising that, although cytC was constitutively released in uninjured Pin $1^{-/-}$mice at significantly higher levels than the levels found in the injured wild-type mice, apoptosis was not observed until injury was performed. These data suggest that cytC release alone is not sufficient to induce apoptosis in vivo. This conclusion is in complete agreement with a previous report in which the injection of cytC was insufficient to induce apoptosis in neuronal cultures that were maintained in NGF (Deshmukh and Johnson, 1998). Clearly, an additional event or events initiated by spinal cord injury are necessary to trigger the apoptotic cascade. Our data indicate that JNK3 activation is one such event that is necessary to initiate the apoptotic cascade under pathological conditions, disengaging the pro-survival function of Pin1 toward Mcl-1.

Another surprising finding in our study is that, although neurons activate the JNK pathway on the basis of $p$-c-Jun staining, the extent of their apoptosis was not affected by JNK3 genotype. A simple explanation may be that neurons activate JNK1/2 predominantly and not JNK3 after spinal cord injury. We consider this scenario unlikely, because JNK3 is expressed in both neurons and oligodendrocytes (data not shown), and the counts of $p$-c$\mathrm{Jun}^{+}$cells among neurons were reduced in the absence of JNK3, albeit it was not statistically significant (supplemental Fig. $2 \mathrm{~A}$, available at www.jneurosci.org as supplemental material). Instead, it is likely that JNK3 is activated among neurons after injury, but it plays a role other than inducing apoptosis. A potential role for JNK3 in neurons is regulating some aspects of autophagic death. Our preliminary data support this possibility, because beclin-1 (myosin-like Bcl-2-interacting) protein levels are affected in JNK3 ${ }^{-/-}$mice (our unpublished results). Alternatively, JNK3 may not regulate cell death but may play roles in relaying the injury signals back to the cell bodies for possible regeneration programs, as suggested by Cavalli and colleagues (2005).

\section{References}

Beattie MS, Harrington AW, Lee R, Kim JY, Boyce SL, Longo FM, Bresnahan JC, Hempstead BL, Yoon SO (2002) ProNGF induces p75-mediated death of oligodendrocytes following spinal cord injury. Neuron 36:375-386
Becker EB, Bonni A (2006) Pin1 mediates neural-specific activation of the mitochondrial apoptotic machinery. Neuron 49:655-662.

Behrens A, Sibilia M, Wagner EF (1999) Amino-terminal phosphorylation of c-Jun regulates stress-induced apoptosis and cellular proliferation. Nat Genet 21:326-329.

Benn SC, Woolf CJ (2004) Adult neuron survival strategies—slamming on the brakes. Nat Rev Neurosci 5:686-700.

Brecht S, Kirchhof R, Chromik A, Willesen M, Nicolaus T, Raivich G, Wessig J, Waetzig V, Goetz M, Claussen M, Pearse D, Kuan CY, Vaudano E, Behrens A, Wagner E, Flavell RA, Davis RJ, Herdegen T (2005) Specific pathophysiological functions of JNK isoforms in the brain. Eur J Neurosci 21:363-377.

Cavalli V, Kujala P, Klumperman J, Goldstein LS (2005) Sunday Driver links axonal transport to damage signaling. J Cell Biol 168:775-787.

Cohen P, Frame S (2001) The renaissance of GSK3. Nat Rev Mol Cell Biol 2:769-776.

Crowe MJ, Bresnahan JC, Shuman SL, Masters JN, Beattie MS (1997) Apoptosis and delayed degeneration after spinal cord injury in rats and monkeys. Nat Med [Erratum (1997) 3:240] 3:73-76.

Demjen D, Klussmann S, Kleber S, Zuliani C, Stieltjes B, Metzger C, Hirt UA, Walczak H, Falk W, Essig M, Edler L, Krammer PH, Martin-Villalba A (2004) Neutralization of CD95 ligand promotes regeneration and functional recovery after spinal cord injury. Nat Med 10:389-395.

Deshmukh M, Johnson Jr EM (1998) Evidence of a novel event during neuronal death: development of competence-to-die in response to cytoplasmic cytochrome $c$. Neuron 21:695-705.

Domina AM, Vrana JA, Gregory MA, Hann SR, Craig RW (2004) MCL1 is phosphorylated in the PEST region and stabilized upon ERK activation in viable cells, and at additional sites with cytotoxic okadaic acid or taxol. Oncogene 23:5301-5315.

Gross A, McDonnell JM, Korsmeyer SJ (1999) BCL-2 family members and the mitochondria in apoptosis. Genes Dev 13:1899-1911.

Harrington AW, Kim JY, Yoon SO (2002) Activation of Rac GTPase by p75 is necessary for c-jun $\mathrm{N}$-terminal kinase-mediated apoptosis. J Neurosci 22:156-166.

Herdegen T, Claret FX, Kallunki T, Martin-Villalba A, Winter C, Hunter T, Karin M (1998) Lasting N-terminal phosphorylation of c-Jun and activation of c-Jun $\mathrm{N}$-terminal kinases after neuronal injury. J Neurosci 18:5124-5135.

Hunot S, Vila M, Teismann P, Davis RJ, Hirsch EC, Przedborski S, Rakic P, Flavell RA (2004) JNK-mediated induction of cyclooxygenase 2 is required for neurodegeneration in a mouse model of Parkinson's disease. Proc Natl Acad Sci USA 101:665-670.

Inoshita S, Takeda K, Hatai T, Terada Y, Sano M, Hata J, Umezawa A, Ichijo $\mathrm{H}$ (2002) Phosphorylation and inactivation of myeloid cell leukemia 1 by JNK in response to oxidative stress. J Biol Chem 277:43730-43734.

Kallunki T, Deng T, Hibi M, Karin M (1996) c-Jun can recruit JNK to phosphorylate dimerization partners via specific docking interactions. Cell 87:929-939.

Kenney AM, Kocsis JD (1998) Peripheral axotomy induces long-term c-Jun amino-terminal kinase-1 activation and activator protein- 1 binding activity by c-Jun and junD in adult rat dorsal root ganglia in vivo. J Neurosci 18:1318-1328.

Kim GM, Xu J, Song SK, Yan P, Ku G, Xu XM, Hsu CY (2001) Tumor necrosis factor receptor deletion reduces nuclear factor- $\kappa \mathrm{B}$ activation, cellular inhibitor of apoptosis protein 2 expression, and functional recovery after traumatic spinal cord injury. J Neurosci 21:6617-6625.

Kim JY, Sun Q, Oglesbee M, Yoon SO (2003) The role of ErbB2 signaling in the onset of terminal differentiation of oligodendrocytes in vivo. J Neurosci 23:5561-5571.

Kuan CY, Yang DD, Samanta Roy DR, Davis RJ, Rakic P, Flavell RA (1999) The Jnk1 and Jnk2 protein kinases are required for regional specific apoptosis during early brain development. Neuron 22:667-676.

Kuan CY, Whitmarsh AJ, Yang DD, Liao G, Schloemer AJ, Dong C, Bao J, Banasiak KJ, Haddad GG, Flavell RA, Davis RJ, Rakic P (2003) A critical role of neural-specific JNK3 for ischemic apoptosis. Proc Natl Acad Sci USA 100:15184-15189.

Liou YC, Ryo A, Huang HK, Lu PJ, Bronson R, Fujimori F, Uchida T, Hunter T, Lu KP (2002) Loss of Pinl function in the mouse causes phenotypes resembling cyclin D1-null phenotypes. Proc Natl Acad Sci USA 99:1335-1340. 
Liou YC, Sun A, Ryo A, Zhou XZ, Yu ZX, Huang HK, Uchida T, Bronson R, Bing G, Li X, Hunter T, Lu KP (2003) Role of the prolyl isomerase Pin1 in protecting against age-dependent neurodegeneration. Nature 424:556-561.

Liu J, Lillo C, Jonsson PA, Velde CV, Ward CM, Miller TM, Subramaniam JR, Rothstein JD, Marklund S, Andersen PM, Brannstrom T, Gredal O, Wong PC, Williams DS, Cleveland DW (2004) Toxicity of familial ALS-linked SOD1 mutants from selective recruitment to spinal mitochondria. Neuron 43:5-17.

Liu X, Kim CN, Yang J, Jemmerson R, Wang X (1996) Induction of apoptotic program in cell-free extracts: requirement for dATP and cytochrome $c$. Cell 86:147-157.

Lu PJ, Wulf G, Zhou XZ, Davies P, Lu KP (1999) The prolyl isomerase Pin1 restores the function of Alzheimer-associated phosphorylated tau protein. Nature 399:784-788.

Marchenko ND, Zaika A, Moll UM (2000) Death signal-induced localization of 553 protein to mitochondria. A potential role in apoptotic signaling. J Biol Chem 275:16202-16212.

Maurer U, Charvet C, Wagman AS, Dejardin E, Green DR (2006) Glycogen synthase kinase- 3 regulates mitochondrial outer membrane permeabilization and apoptosis by destabilization of MCL-1. Mol Cell 21:749-760.

Mohit AA, Martin JH, Miller CA (1995) p49 ${ }^{3 \mathrm{~F} 12}$ kinase: a novel MAP kinase expressed in a subset of neurons in the human nervous system. Neuron 14:67-78.

Nijhawan D, Fang M, Traer E, Zhong Q, Gao W, Du F, Wang X (2003) Elimination of $\mathrm{Mcl}-1$ is required for the initiation of apoptosis following ultraviolet irradiation. Genes Dev 17:1475-1486.

Okuno S, Saito A, Hayashi T, Chan PH (2004) The c-Jun N-terminal protein kinase signaling pathway mediates bax activation and subsequent neuronal apoptosis through interaction with bim after transient focal cerebral ischemia. J Neurosci 24:7879-7887.

Shaulian E, Karin M (2002) AP-1 as a regulator of cell life and death. Nat Cell Biol 4:E131-E136.

Totoiu MO, Keirstead HS (2005) Spinal cord injury is accompanied by chronic progressive demyelination. J Comp Neurol 486:373-383.

Tournier C, Hess P, Yang DD, Xu J, Turner TK, Nimnual A, Bar-Sagi D, Jones SN, Flavell RA, Davis RJ (2000) Requirement of JNK for stress-induced activation of the cytochrome $c$-mediated death pathway. Science 288:870-874.

Wulf G, Finn G, Suizu F, Lu KP (2005) Phosphorylation-specific prolyl isomerization: is there an underlying theme? Nat Cell Biol 7:435-441.

Yaffe MB, Schutkowski M, Shen M, Zhou XZ, Stukenberg PT, Rahfeld JU, Xu J, Kuang J, Kirschner MW, Fischer G, Cantley LC, Lu KP (1997) Sequence-specific and phosphorylation-dependent proline isomerization: a potential mitotic regulatory mechanism. Science 278: 1957-1960.

Yang DD, Kuan CY, Whitmarsh AJ, Rincon M, Zheng TS, Davis RJ, Rakic P, Flavell RA (1997) Absence of excitotoxicity-induced apoptosis in the hippocampus of mice lacking the Jnk3 gene. Nature 389:865-870.

Yoshida K, Behrens A, Le-Niculescu H, Wagner EF, Harada T, Imaki J, Ohno S, Karin M (2002) Amino-terminal phosphorylation of c-Jun regulates apoptosis in the retinal ganglion cells by optic nerve transection. Invest Ophthalmol Vis Sci 43:1631-1635.

Zhong D, Bajaj SP (1993) A PCR-based method for site-specific domain replacement that does not require restriction recognition sequences. Biotechniques 15:874-878.

Zhong Q, Gao W, Du F, Wang X (2005) Mule/ARF-BP1, a BH3-only E3 ubiquitin ligase, catalyzes the polyubiquitination of $\mathrm{Mcl}-1$ and regulates apoptosis. Cell 121:1085-1095. 